\title{
Reduced and Unreduced Phrasal Comparatives
}

\author{
Rajesh Bhatt ${ }^{1}$ and Shoichi Takahashi ${ }^{1,2}$ \\ \{bhatt,shoichi\}@linguist.umass.edu \\ ${ }^{1}$ University of Massachusetts at Amherst, ${ }^{2}$ University of Tokyo
}

\begin{abstract}
Degree heads combine with individual (John is taller than [Mary]) as well as clausal arguments (John is taller than [Mary is]). Does the degree head have the same meaning in these two argument structures? Two kinds of answers have been proposed in the literature: i. there is a single meaning where the degree head combines with a degree predicate (2-place er), with a reduction operation that derives the DP argument from a degree predicate denoting clausal argument, and ii. there are distinct meanings for each argument structure, one combining with an individual denoting DP (3-place -er) and the other with a degree predicate denoting clause (2-place -er). We show that languages vary in which of these answers they choose: English goes for option I and Hindi-Urdu and Japanese for versions of option II. Despite this surface variation, we argue that the crosslinguistic distribution of 2-place and 3-place -er is not in itself subject to crosslinguistic parametrization; they are just syntactic projections of the basic meaning of comparison. The differences between these languages are therefore derived from the morphosyntactic properties of 'than', considerations of directionality, and a preference for minimal structure.
\end{abstract}

\section{Multiple Routes to A Single Meaning}

Natural languages often provide instances where two distinct structures map to the same meaning. The much-studied operation of passivization could be taken to provide an instance of two structures, the active and the passive, mapping to the same meaning. In this paper we are interested in examining a similar pair from the domain of comparative constructions. Many languages allow comparative meanings to be expressed by means of a clausal comparative (1a) and a phrasal comparative (1b). These seem to have the same meaning but differ in the category of the constituent that than combines with. In the case of a clausal comparative, than combines with a clause that has undergone some reduction operation and in the case of a phrasal comparative, than combines with a DP. If we believe that the surface structures in (1) are directly the input to interpretation, we are led to the conclusion that the comparative degree head -er has a distinct semantic entry in the clausal comparative and the phrasal comparative. More specifically, if we assume following von Stechow (1984) that the clausal complement of than denotes a degree description, then the degree head in a clausal comparative combines with a degree description while the degree head in a phrasal comparative combines with an individual.

(1) Comparison:

a. Clausal Comparative:

John is taller than [Bill is].

- a degree head that combines with a clause

2-place -er: 2 arguments - the extent of John's tallness, the extent of Bill's tallness 
b. Phrasal Comparative:

John is taller than [Bill].

- a degree head that combines with an individual

3-place -er: 3 arguments - Bill, John, the property of tallness

Further assumptions, to be made explicit in this paper, lead to the observation that clausal comparatives involve a 2-place -er, which combines with two degree descriptions, while phrasal comparatives involve a 3-place -er, which combines with two individual arguments and a predicate of degrees and individuals.

The question that arises at this point is whether we need both kinds of degree heads within and across languages. An initial observation that could be taken to argue against having both kinds of degree heads is that while there are many languages which have both phrasal and clausal comparatives, there do not seem to be any languages where morphologically distinct degree heads are used for the two kinds of comparatives. Nevertheless we show that languages do make use of both kinds of degree heads. This raises the question of the crosslinguistic and intralinguistic distribution of the different kinds of degree heads. Here a number of factors come into play and our paper is an attempt to tease these apart.

The simplest kind of solution to the distribution question namely that clausal comparatives use the 2-place head and phrasal comparatives use the 3-place head is shown to be incorrect. While clausal comparatives always involve a 2-place head, the situation with phrasal comparatives is more involved. Whether a phrasal comparative in a given language uses a 2-place head or a 3-place head depends in part on the availability of reduction operations within the than-complement in that language. In certain cases, because of the applicability of reduction operations, the than-phrase in a phrasal comparative could be a reduced clause and a 3-place degree head that combines with an individual might not be necessary. This seems to be the case with English and German (see Lechner (2001), Lechner (2004)). In cases where reduction operations are unavailable, a 3-place -er is forced, as argued for Hindi-Urdu in Bhatt and Takahashi (2007).

But reduction operations do not fully determine the availability of 3-place -er. We show that in Japanese, reduction operations are available but 3-place -er is still attested. Certain phrases that could be treated as reduced clauses are not treated as such. The question of the distribution of a particular degree head in a particular language reduces to the question of what constrains/requires the application of particular reduction operations. We argue that the answer to both these questions comes from an interaction between the morphosyntactic properties of comparative markers like than, a preference for minimal structure, and directionality related asymmetries. Ultimately there is no crosslinguistic variation in the distribution of 2-place and 3 -place degree heads. They are merely different projections of the same meaning and if a language has one, it has the other, which is why no language realizes the two distinctly. But languages differ in the environment where one or the other degree head may be used leading to the observed crosslinguistic differences.

\subsection{2-place -er and Clausal Comparatives}

Let us begin with an introduction to clausal comparatives and the 2-place degree head that goes with them. In English clausal comparatives (see 2a), the than-phrase combines with a clause which denotes a degree expression. We assume that there is a silent degree predicate inside the Bill is clause. This silent degree predicate is overt in (2b), the Hindi-Urdu counterpart of (2a). 
Here the comparative marker -se 'than' combines with a degree denoting pronoun which refers to the correlative degree clause 'how tall Bill is'. In both cases, the degree head -er combines with a degree description.

(2) Clausal:

a. John is taller than [Bill is].

b. Hindi-Urdu:

[Bill jitnaa lambaa hai] [John us-se zyaadaa lambaa hai]

Bill how tall is John that-than more tall is

'John is taller than Bill is.'

Given the syntax we assume below where the degree head forms a constituent with the thanclause, this yields a 2-place predicate. ${ }^{1}$

(3) P, Q are degree predicates (sets of degrees)

a. $-\operatorname{er}(\mathrm{P})(\mathrm{Q}) \leftrightarrow \exists d[Q(d) \wedge \neg P(d)]$

b. -er [ $\lambda d$. Bill is $d$-tall] [ $\lambda d$. John is $d$-tall]

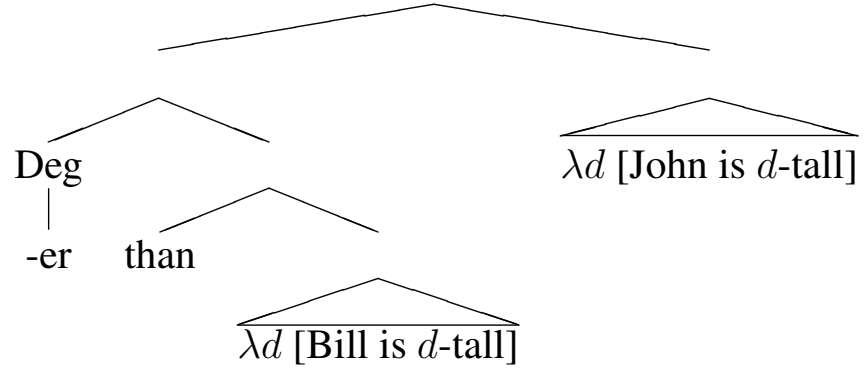

The 2-place -er is also useful for handling cases where the complement of than directly names a degree.

(4) a. John is taller than six feet.'

b. Hindi-Urdu:

Atif-ne tiin-se zyaadaa kitaabẽ khariid-ii thĩ:

Atif-Erg three-than more books.f buy-Pfv.f be.Pst.FPl

'Atif bought more than three books.'

In general, if a languages allows than to combine directly with a degree name, we can assume that it has a 2-place degree head. These cases also reveal that 2-place degree heads are not limited to clausal comparatives. Clausal comparatives always require a 2-place degree head but so do ostensibly phrasal comparatives like (4).

\footnotetext{
${ }^{1}$ The exact syntax of how the DegP combines with the rest of the clause is not crucial for our proposal. Our proposal would also be consistent for example with analyses where the Deg head does not form a constituent with the degree clause (Kennedy (1997)). What is crucial is that the than-clause is treated as a degree description.
} 


\subsection{3-place -er and Phrasal Comparatives}

On the surface, -er in phrasal comparatives combines with an individual, not a degree description. We refer to the complement of the than-phrase in a phrasal comparative as the remnant and to the constituent in the main clause that is contrasted with the remnant as the associate. Thus in (5a), Bill is the remnant and John is the associate.

(5) Phrasal:

a. John is taller than Bill.

b. Hindi-Urdu:

John Bill-se zyaadaa lambaa hai

John Bill-than more tall is

'John is taller than Bill.'

This aspect of phrasal comparatives leads to two kinds of analyses. The first kind of analyses can be dubbed Reduction Analyses because they assume that the complement of than is derived via reduction from a larger clausal constituent which stands for a degree description much like in clausal comparatives.

(6) a. John is taller [than [Bill is tall]].

b. More students ate apples [than [students ate bananas]].

Once such a reduction operation is assumed, the need for a distinct 3-place -er that combines with individuals disappears and we can limit ourselves to one -er which takes two degree descriptions as arguments. Particular instantiations of the Reduction Analysis differ on exactly what reduction operation is relevant (Gapping, Conjunction Reduction: Lechner 2001, 2004; TP-ellipsis, Stripping: Merchant 2007) and what the size of the reduced object is (Pancheva 2006, 2007).

The second kind of analyses can be dubbed Direct Analyses as they do not assume a reduction operation and as a result the degree head combines directly with the overt complement of the than-phrase (see Heim (1985)). This complement denotes an individual, not a degree argument. This necessitates a new lexical entry for the degree head: a 3-place -er that combines with two individual arguments and a predicate of individuals and degrees.

(7) $\quad-\operatorname{er}(\mathrm{x})(\mathrm{P})(\mathrm{y}) \leftrightarrow \exists d[P(y, d) \wedge \neg P(x, d)]$

The predicate of individuals and degrees is created by movement of the associate and the degree operator. We assume the following steps. First the associate moves creating a predicate of individuals. Next the degree phrase moves and targets the predicate of individuals created by the movement of the associate. ${ }^{2}$ This is an instance of 'parasitic scope' - a case where a movement operation targets a position created by a preceding movement (see Nissenbaum 2000, Barker 2007, Kennedy \& Stanley 2008).

(8) John is taller than Mary.

\footnotetext{
${ }^{2}$ The Deg head presumably combines with the than-phrase via Late Merge as in Bhatt and Pancheva (2004), Takahashi and Hulsey (2008) but this is not crucial.
} 

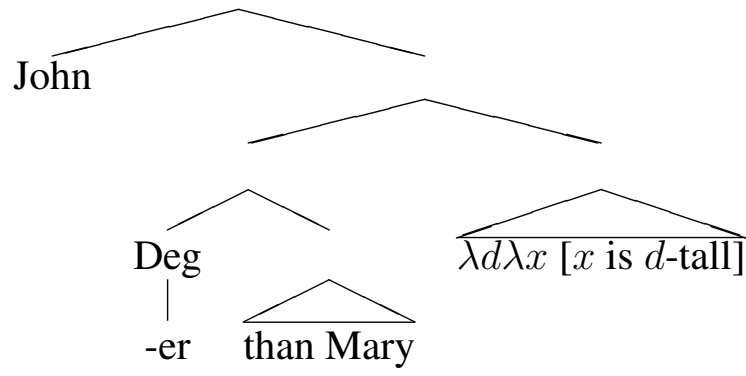

$\exists d[\operatorname{tall}(\mathrm{j}, \mathrm{d}) \wedge \neg \operatorname{tall}(\mathrm{m}, \mathrm{d})]$

The clearest motivation for the movement of the associate comes from cases like (9), where the relevant predicate of individuals and degrees does not exist on the surface. Movement of the associate is necessary to create such a predicate.

(9) More students read LGB than the MP.

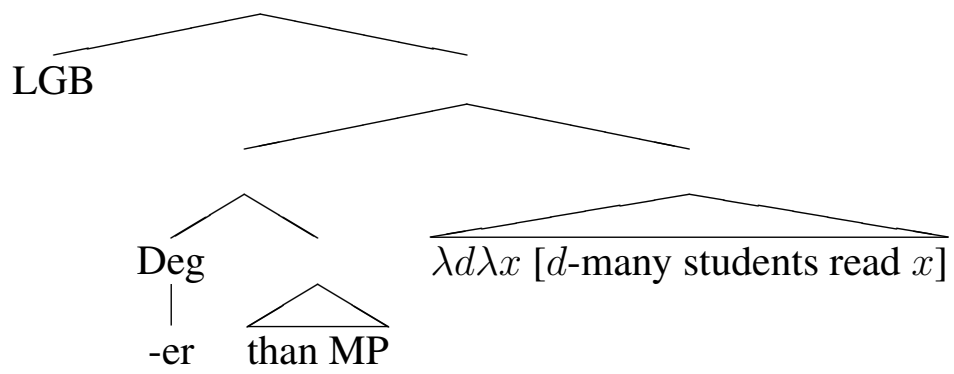

$$
\begin{aligned}
\exists d[\exists x[\operatorname{students}(\mathrm{x}) & \wedge \operatorname{card}(\mathrm{x})=\mathrm{d} \wedge \operatorname{read}(\mathrm{x}, \mathrm{LGB})] \\
\wedge \neg \exists x[\operatorname{students}(\mathrm{x}) & \wedge \operatorname{card}(\mathrm{x})=\mathrm{d} \wedge \operatorname{read}(\mathrm{x}, \mathrm{MP})]]
\end{aligned}
$$

The data from Hindi-Urdu and Japanese phrasal comparatives provides evidence in support of associate movement. Unlike English where the postulated movement of the associate is a covert movement, in these languages the relevant movement has to be overt and is subject to the usual constraints on overt movement.

\section{Binding and the Direct Analysis in English}

The Reduction Analysis and the Direct Analysis differ in the predictions they make about the binding properties of the remnant. In the Reduction Analysis, the remnant is inside a larger clausal structure which is isomorphic in most ways to the matrix clause. In particular, the remnant occupies a position within the reduced clause that is parallel to the position occupied by its associate in the matrix clause. This leads to the expectation that the binding properties of the remnant will be related to the structural position of its associate. The Direct Analysis makes a very different prediction. There is no reduced clause on the Direct Analysis. Moreover since the remnant does not form a constituent with the associate, we do not expect there to be any dependency between the binding properties of the remnant and those of the associate. The remnant has the external syntax of a PP and one would expect it to have the binding properties of a PP in the same structural location. 
So what are the facts? What c-commands the remnant? Building upon Lechner (2004)'s observations, we present the following generalization:

(10) The remnant is c-commanded by everything that c-commands the associate.

Consider for example (11a) and (12a), where we have a pronoun that c-commands the associate. We see that this pronoun cannot co-refer to an R-expression inside a remnant. If the pronoun does not c-command the associate, as in (11/12b), then coreference is possible.

a. pronoun c-commands associate: *More people talked to $\operatorname{him}_{i}$ about Sally than about Peter $_{i}$ 's sister. (Control: More people talked to $\operatorname{Peter}_{i}$ about Sally than about his ${ }_{i}$ sister. )

b. pronoun does not c-command associate:

More people talked to Sally about $\operatorname{him}_{i}$ than to Peter $_{i}$ 's sister.

(Control: More people talked to Sally about $\operatorname{Peter}_{i}$ than to his ${ }_{i}$ sister.)

(12) (Context: Peter, Peter's sister, and Sally are taking part in a race. People are betting on their prospects.)

a. pronoun c-commands associate:

*More people expect $\operatorname{him}_{i}$ to overtake Sally than Peter ${ }_{i}$ 's sister.

(=*More people expect him $_{i}$ to overtake Sally than expect him ${ }_{i}$ to overtake Peter ${ }_{i}$ 's sister.)

(Control: More people expect Peter ${ }_{i}$ to overtake Sally than his ${ }_{i}$ sister.

(= More people expect Peter ${ }_{i}$ to overtake Sally than expect Peter ${ }_{i}$ to overtake his ${ }_{i}$ sister.))

b. pronoun does not c-command associate:

(?)More people expect Sally to overtake $\operatorname{him}_{i}$ than Peter $_{i}$ 's sister.

(= More people expect Sally to overtake $\operatorname{him}_{i}$ than expect Peter ${ }_{i}$ 's sister to overtake $\operatorname{him}_{i}$.)

(Control: More people expect Sally to overtake Peter ${ }_{i}$ than his ${ }_{i}$ sister.

(= More people expect Sally to overtake Peter ${ }_{i}$ than expect Sally to overtake his ${ }_{i}$ sister.))

There is a clear contrast between (11/12b) and the ungrammatical (11/12a). It is crucial to note that internal arguments of the verb do not always c-command the remnant. We have already seen this in (11/12b). This point is also made by the examples in (13). ${ }^{3}$

(13) a. Mary gave $\operatorname{him}_{i}$ more presents than $\mathrm{John}_{i}$ 's mother. (= Mary gave $\operatorname{him}_{i}$ more presents than $\mathrm{John}_{i}$ 's mother gave him ${ }_{i}$.)

b. Mary gave more presents to $\operatorname{him}_{i}$ than $\mathrm{John}_{i}$ 's mother. (= Mary gave more presents to $\operatorname{him}_{i}$ than $\operatorname{John}_{i}$ 's mother gave to $\operatorname{him}_{i}$.)

\footnotetext{
${ }^{3}$ We do not understand why (12b) is mildly deviant compared to (11b) and the examples in (13). We speculate that there is a preference for choosing the matrix subject as an associate for a DP remnant. This is, of course, impossible in (12b) but we believe that this contributes a mild deviance. In (11), the remnants are PPs and so this factor is not relevant. In (13), the associate is in fact the matrix subject and so the preference is satisfied.
} 
If the internal arguments of a verb always c-commanded the remnant, (11/12b) and (13) would have been ungrammatical. The relationship that we find is more indirect and is mediated by the associate.

The generalization above does not follow from the Direct Analysis straightforwardly. Under the Direct Analysis a remnant is merged with a degree head outside of the c-command domain of the base-generated position of an associate and there is no movement dependency between the LF position of the remnant and the base-generated position of the associate. Thus, one would expect a situation in which a remnant is not c-commanded by an item that c-commands an associate. This can be seen by examining the LF representations assigned by the Direct Analysis to (11a) and (11b) respectively.

(14) a. *More people talked to him ${ }_{i}$ about Sally than about Peter $_{i}$ 's sister.

LF: [Sally [-er [than Peter ${ }_{i}$ 's sister]

$\lambda d . \lambda x$. [d-many people talked to $\operatorname{him}_{i}$ about $\left.\left.\left.x\right]\right]\right]$

b. More people talked to Sally about him ${ }_{i}$ than to Peter $_{i}$ 's sister.

LF: [Sally [-er [than Peter $_{i}$ 's sister]

$\lambda d . \lambda x .\left[d\right.$-many people talked to $x$ about him $\left.\left.\left._{i}\right]\right]\right]$

In neither of the LF representations in (14) does the pronoun in the matrix clause c-command the remnant. Therefore the Direct Analysis does not predict the contrast between (11a) and (11b). ${ }^{4}$

In contrast, the generalization in (10) can be captured under a Reduction Analysis because according to such an analysis, the complement of than is a reduced clause that is isomorphic in most respects to the main clause. To a first approximation, the remnant occupies the same position within the elided clause as its associate does in the matrix clause. Hence, everything that c-commands an associate c-commands a remnant. Let us see how a Reduction Analysis could handle the contrast in (11).

a. *More people talked to $\operatorname{him}_{i}$ about Sally than about Peter $_{i}$ 's sister.

Underlying Structure:

*More people talked to him $_{i}$ about Sally

[than $\lambda d$. d-many people talked to him about Peter $_{i}$ 's sister]

b. More people talked to Sally about $\operatorname{him}_{i}$ than to Peter ${ }_{i}$ 's sister.

Underlying Structure:

*More people talked to Sally about him h $_{i}$

[than $\lambda d$. $d$-many people talked to Peter $_{i}$ 's sister about him ${ }_{i}$ ]

\footnotetext{
${ }^{4}$ Another place where the Direct Analysis and the Reduction Analysis diverge from each other is in cases where the associate is a pronoun. (10) is silent about such cases. The LFs assigned by the Direct Analysis lead us to expect that a pronominal associate should not be able to corefer with an R-expression contained in the remnant. This is because under the Direct Analysis the associate c-commands the remnant at LF. But coreference is allowed in such cases.

i. $\quad$ a. More people talked to Sally about him him $_{i}$ thabout Peter $_{i}$ 's sister.

b. More people talked to him $_{i}$ about Sally than to Peter $_{i}$ 's sister.

The Reduction Analysis does not prohibit coreference in these cases. So these examples show that the Direct Analysis cannot be the only analysis available for English phrasal comparatives. But they do not show that the Direct Analysis is unavailable. For that we need the cases covered by (10).
} 
The structures in $(15 \mathrm{a} / \mathrm{b})$ seem to involve ellipsis of non-constituents. There are empirical reasons to restrict ellipsis operations to constituents. This leads us to an analysis like Merchant (2006), where the remnant moves out of the elided constituent prior to the ellipsis operator applying. Support for the claim that the remnant undergoes movement comes from examples that look like putative counterexamples to (10).

(16) a. More people introduced $\operatorname{him}_{i}$ to Sally than to the popstar that Peter $_{i}$ actually wanted to meet. (Carl Pollard p.c.)

b. More people introduced $\operatorname{him}_{i}$ to Sally than to the woman that Peter $_{i}$ likes.

In $(16 \mathrm{a}, \mathrm{b})$, the pronoun c-commands the associate and yet is able to corefer with a name inside the remnant, contradicting (10). But note that the offending name in $(16 \mathrm{a}, \mathrm{b})$ is contained within an adjunct, a relative clause. What we have here is an instance of the familiar adjunct-argument Condition C obviation asymmetry. The contrast in (17) supports this characterization.

(17) a. *More people told $\operatorname{him}_{i}$ the rumor that Mary was a thief than the rumor that $\mathrm{John}_{i}$ was a drug addict.

b. More people told $\operatorname{him}_{i}$ their day to day stories than the rumors that $\mathrm{John}_{i}$ actually wanted to hear.

In (17a), the name is contained within a complement and there is no Condition C obviation. But in $(17 b)$, like in $(16 a, b)$, the name is contained within a relative clause adjunct and Condition $\mathrm{C}$ is obviated. The existence of this asymmetry indicates that an analysis along the lines of (15) is incomplete. Other environments where this asymmetry is found involve overt movement of the maximal projection containing the name. This suggests that the remnant in phrasal comparatives also undergoes overt movement followed by elision of the remainder of the than-constituent as in Merchant (2006). With this modification, the facts in (16) and (17) no longer constitute a real counterexample to (10). The adjunct relative can be merged with the remnant after the remnant has moved out of the elided constituent and thus does not have to be in the c-command domain of a pronoun that c-commands the remnant before movement as in Lebeaux (1990). Complements must be merged early and so a name within a complement must be within the c-command domain of any pronoun that c-commands the remnant before movement.

We take our analysis of the binding generalization in (10) to show that the Direct Analysis cannot be at work in English. If it was available, it would allow the unavailable coreference in (11/12a). Only the Reduction Analysis is available in English. ${ }^{5}$ And in fact, as we will see, in languages where the Direct Analysis is available, we do not find evidence for the binding generalization.

\footnotetext{
${ }^{5}$ That the Direct Analysis is not an option for English and that phrasal comparatives in English must receive a Reduction Analysis is a point that we take to have been made at length in Lechner (2001)/Lechner (2004) and Pancheva (2007). For this reason, we do not address here in any detail the various challenges to a uniformly clausal treatment of English phrasal comparatives. But we note that many putative challenges (see Hankamer (1973), Brame (1983)) to a reduced clausal analysis come from the incorrect assumption that the reduced clause has the same size as an unreduced finite clausal complement of than. For example, extraction is often considered a serious challenge for a Reduction Analysis (Who is John taller than $t_{i}$ ? vs. *Who is John taller than $t_{i}$ is?). But in fact the full range of extraction facts support a Reduction Analysis. In languages with a Direct Analysis, any complement of than can be questioned irrespective of its associate. In English, however, extraction of than-phrases with non-subject associates is severely degraded (*To whom ${ }_{i}$ did John give more books to Mary than $t_{i}$ ?). It has been suggested to us that the pattern of extraction parallels extraction out of small clauses. Finally we note that cases like more than $n$ have also been argued to involve clausal structures; see Hackl (2001) for details.
} 


\section{Hindi-Urdu: A case for the Direct Analysis}

We have argued that the Direct Analysis is not available in English. One could imagine that this language particular unavailability could follow from a more general crosslinguistic unavailability of the 3-place -er assumed by the Direct Analysis. We now show that the 3-place -er is in fact available in some languages. Hindi-Urdu is shown to be a language where the Reduction Analysis is infeasible. Instead the Direct Analysis, which requires a 3-place -er, can be seen to be at work. We begin with a basic introduction to the salient aspect of Hindi-Urdu phrasal comparatives.

\subsection{Basic Description}

Phrasal comparatives in Hindi-Urdu involve a degree head zyaadaa 'more' and a than-phrase, which is marked by the postposition -se. This postposition is also used to mark instruments and locative and temporal from. With most but not all adjectives, zyaadaa 'more' is optional. The optionality is independent of whether the adjective is predicative or attributive. With nonadjectival comparatives, zyaadaa is obligatory. We illustrate the point here with a nominal comparative but it is also true of comparatives on adverbs that are distinct from adjectives such as aksar 'often'. 6

a. adjectival comparative with optional zyaadaa 'more':

Atif Boman-se (zyaadaa) lambaa hai

Atif.m Boman-than more tall be.Prs.Sg

'Atif is taller than Boman.'

b. adjectival comparative that requires zyaadaa 'more':

is project-ke-baare-me Atif Boman-se *(zyaadaa) utsuk hai

this project-about Atif.m Boman-than more eager be.Prs.Sg

'Atif is more eager about this project than Boman.'

c. non-adjectival comparatives always require zyaadaa 'more':

Atif-ne Boman-se zyaadaa kitaabẽ parh-ĩ:

Atif-Erg Boman-than more books.f read-Pfv.FPl

'Atif read more books than Boman.'

In all the examples in (18), the than-phrase precedes zyaadaa 'more'. This is actually a requirement. If the than-phrase follows zyaadaa 'more', we end up with ungrammaticality. This is the case irrespective of whether zyaadaa is overt or not.

more $>$ remnant: *

\footnotetext{
${ }^{6}$ The adjectives versus non-adjective distinction can be seen as parallel to the English pattern by which only adjectives combine directly with -er. Non-adjectives require more, which has been analyzed as the comparative form of an adjectival many/much that is required for the -er to combine with a non-adjective. Why some adjectives in Hindi-Urdu require an overt zyaadaa 'more' is parallel to the fact that not all adjectives in English combine directly with -er. In general, Hindi-Urdu adjectives which take internal arguments (e.g. utsuk 'eager about', paas 'near', gussaa 'angry at') require an overt zyaadaa, while adjectives that measure physical attributes such height and weight do not. Adjectives that measure abstract attributes such as intelligence and kindness fall in an in-between zone.
} 
a. *Atif (zyaadaa) lambaa Boman-se hai

Atif.m more tall Boman-than be.Prs.Sg

'Atif is taller than Boman.'

b. *Atif-ne zyaadaa kitaabẽ Boman-se paṛh-ĩ:

Atif-Erg more books Boman-than read-Pfv.FPl

'Atif read more books than Boman.'

As long as the than-phrase precedes more, no further restrictions are imposed on the relative order of the associate and the than-phrase: the than-phrase may precede the associate and there may be material between the associate and the than-phrase.

This precedence restriction between the more and the than-phrase makes sense once we note that the than-phrase is an argument of more and arguments precede their heads in HindiUrdu. This is in fact a typological property of head-final languages. We assume that in its merge configuration, the than-phrase precedes the degree head. From here the than-phrase can undergo further scrambling to the left leading to configurations where it might be discontinuous from the degree head. ${ }^{7}$ An explicit discussion of these steps is presented in $§ 3.5$.

\subsection{Conditions on Associates and Remnants}

The associate can be a PP or a DP and have any grammatical function but the remnant can only be a bare DP which is marked by than, which is realized by the postpositional -se.

a. associate $=$ nominative subject

John Bill-se (zyaadaa) lambaa hai

John.m Bill-than more tall.MSG be.Prs.Sg

'John is taller than Bill.'

b. associate $=$ ergative subject

Atif-ne Boman-se zyaadaa kitaabẽ paṛh-ĩ:

Atif-Erg Boman-than more books.f read-Pfv.FPl

'Atif read more books than Boman.'

c. associate $=$ dative $\mathrm{IO}$ :

Atif-ne Mina-ko Tina-se zyaadaa tohfe diye

Atif-Erg Mina-Dat Tina-than more presents.m give.Pfv.MP1

\footnotetext{
${ }^{7}$ Anoop Mahajan (p.c.) has pointed out to us that the precedence restriction is lifted when the than-phrase is moved to the right of verb.

i. zyaadaa kitaabẽ paṛh-ĩ: thĩ: Atif-ne Boman-se more books.f read-Pfv.FPl be.Pst.FPl Atif-Erg Boman-than

'Atif had read more books than Boman.' (sentence is emphatic, could be used to refute a claim that Boman had read more books than Atif.)

We do not attempt an analysis of this intriguing fact because we are not certain about how to analyze rightward movement. If we were to assume that rightward movement is merely movement of DPs to the right, then the acceptability of (i) would follow. (i) would just involve a scrambling of the than-phrase to the right and we independently know that than-phrases can be scrambled out of the AP. But much work on rightward movement (Kayne (1994), Mahajan (1997), Bhatt and Dayal (2007) i.a.) has concluded that apparent cases of rightward movement should not be analyzed as rightward movement of DPs. Hopefully the issue raised by (i) will receive an explanation under the proper analysis of rightward movement.
} 
'Atif gave more presents to Mina than to Tina.'

d. associate $=$ locative PP

Amrika-me Rus-se zyaadaa log rah-te haiN
America-in Russia-than more people stay-Hab.MSg be.Prs.Pl
'More people live in America than in Russia.'

The absence of case-marking on the remnant can lead to ambiguity - (20c), for example, can also be interpreted with the subject as an associate.

The facts in (20) fit well with a Direct Analysis, where the remnant XP is directly a complement of -se 'than'. - se is postpositional and can only combine with DPs. As a result cases with PP or adverbial remnants are severely ungrammatical. Furthermore phrasal comparatives in Hindi-Urdu only allow for a single remnant. In a clear contrast with English, multiple remnants are completely impossible. We refer to this fact as the Single Remnant Restriction.

a. Tina read more books today than Pim yesterday.

b. *Tina-ne aaj [Pim kal-se] zyaadaa kitaabẽ parh-1̃:

Tina-Erg today Pim yesterday-than more books.f read-Pfv.FPl

intended: 'Tina read more books today than Pim yesterday.'

To convey this meaning, a clausal structure, which is realized by a correlative, must be used.

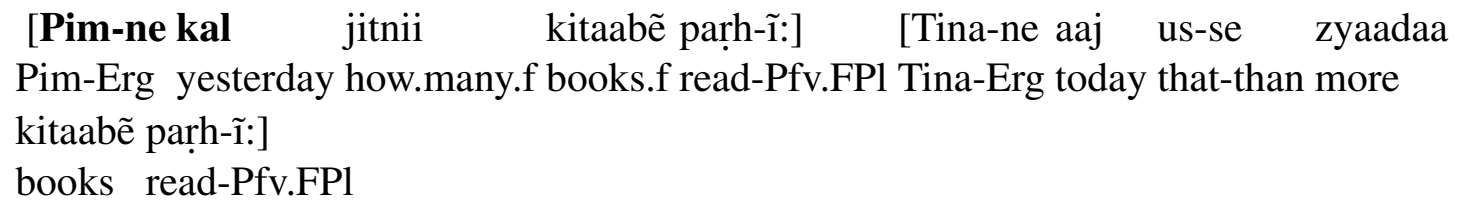

Literally: 'How many books Pim read yesterday, Tina read more books than that today.'

Lechner's Reduction Analysis offers a uniform treatment of comparatives with multiple remnants like (21a) and cases with a single remnant. But under such an analysis the Single Remnant Restriction found in Hindi-Urdu is unexpected.

The Direct Analysis, however, predicts the Single Remnant Restriction. This is because there is no straightforward way to generalize the 3-place -er to handle cases with multiple remnants. One could imagine extending a 3-place -er which takes two individual arguments and a predicate with one individual and one degree argument to a 5-place -er which takes four individual arguments and a predicate of one degree and two individual arguments. But this 5place -er does not fit what the syntax gives us. The two XPs in the remnant form a constituent that combines with than and -er cannot look into this constituent and extract its arguments. More generally cases with multiple remnants constitute a clear case where the than-phrase cannot be taken to be combining with an individual.

The absence of multiple remnants shows that a Direct Analysis is a viable option for phrasal comparatives in Hindi-Urdu and that a Reduction Analysis of the sort proposed by Lechner is not viable for the Hindi-Urdu data. ${ }^{8}$

\footnotetext{
${ }^{8}$ An alternative Reduction Analysis proposed in Merchant (2006) is in fact able to capture the Single Remnant Restriction. Merchant assumes that the remnant in Greek phrasal (apo) comparatives moves out of the comparative clause into the domain of apo 'from/than' and thus becomes for all intents and purposes an object of apo. The Single Remnant Restriction is taken to follow from the assumption that exactly one DP may appear in the domain of a preposition. Merchant's analysis for Greek apo comparatives involves ellipsis of the comparative clause and parallels analyses of sluicing. In particular, we find that Greek disallows PP associates in apo comparatives because
} 
A Reduction Analysis is ruled out for Hindi-Urdu because of a language particular interaction between the Hindi-Urdu than, -se, and finite clauses. The relevant reduction processes that could yield the Reduction Analysis, such as Sluicing and Gapping, seem to be restricted to finite clauses in this language. However, finite clauses can never appear as complements of -se, or for that matter any postpositional element in Hindi-Urdu. This prohibition on postpositions combining with finite clauses has significant consequences for the syntax of Hindi-Urdu. Thus Hindi-Urdu systematically lacks any environment where a P-like element directly combines with a finite clause such as since and until clauses. ${ }^{9}$

a. John has been happy [since [Mary arrived]].

b. *John [Mary aa-ii hai]-se khush hai John Mary come-Pfv.f be.Prs.Sg-from happy be.Prs.Sg

To achieve this meaning, a correlative construction must be used where the finite clause complement of the postposition appears as a correlative which is associated with a pronoun that is the complement of the postposition.

[jab-se Mary aa-ii hai] [tab-se John khush hai] when-from Mary come-Pfv.f be.Prs.Sg then-from John happy be.Prs.Sg

'John has been happy since Mary arrived.'

\subsection{A Precedence Constraint}

An important aspect of the Direct Analysis is that it assumes that there is a configuration in which -er combines with its two individual arguments and a predicate of individuals and degrees.

\section{[Associate [Remnant -er $[\lambda d . \lambda x . \operatorname{Pred}(\mathrm{x}, \mathrm{d})]]]$}

When the associate is the subject, it is already in the right place to combine with the -er.

$$
\text { John [[than Mary] -er }[\lambda d . \lambda x .[\operatorname{tall}(\mathrm{x}, \mathrm{d})]]]
$$

But when the associate is not the subject, it must undergo movement to appear as an argument of -er and thereby create the compared predicate. If English had access to a Direct Analysis, this movement would be an instance of covert QR.

$$
\begin{aligned}
& \text { More people read LGB than the MP. } \\
& \text { LGB }[[\text { than MP] -er }[\lambda d . \lambda x \text {. }[\operatorname{read}(d \text {-many people, } \mathrm{x})]]]
\end{aligned}
$$

the derivation of such comparatives would involve movement of a DP out of the complement of a preposition in the comparative clause. Greek does not allow P-stranding and therefore the analysis correctly predicts the impossibility of PP-associates. Unfortunately this proposal does not carry over to Hindi-Urdu. Hindi-Urdu, like Greek, does not allow P-stranding. Yet PP associates are grammatical as shown in (20d).

${ }^{9}$ This inability of postpositions in Hindi-Urdu to combine with finite clauses is plausibly related to the fact that Hindi-Urdu has head-initial finite complementizers. As a result, the relevant configurations run afoul of Holmberg (2000)/Biberauer et al (2008)'s Final Over Final Constraint (FOFC) by which a head-initial XP cannot be immediately dominated by a head-final phrase. 
We therefore expect that surface structures like (27) will be deviant in languages where covert scope shifting operations are not freely available. Hindi-Urdu is such a language. Sentences in the base order do not display scope ambiguity in contrast to the corresponding structures in English. Only surface scope is available. To get the inverse scope reading, overt scrambling is necessary (see Nevins \& Anand 2003 for some qualifications).

a. some > all, unavailable: all $>$ some

kisi larke-ne har tiicar-se aashirvaad liyaa

some boy-Erg every teacher-from blessing.m take.Pfv.MSg

'Some boy took blessings from every teacher.'

b. all > some, also available: some $>$ all

har tiicar-se kisi larke-ne aashirvaad liyaa

every teacher-from some boy-Erg blessing.m take.Pfv.MSg

'Some boy took blessings from every teacher.'

(29a) shows that the prediction about the deviance of surface structures like (27) in Hindi-Urdu is borne out. (29b) shows that scrambling of the associate allows the associate to be in a position where it can combine with -er, ameliorating the deviance found in (29a).

a. remnant $>$ more $>$ associate

*MP-se zyaadaa logõ-ne LGB parh-ii

MP-than more people-Erg LGB.f read-Pfv.f

'More people read LGB than MP.' (intended, but unavailable)

(available reading: People read LGB to a greater extent than they read MP.)

LF: *[[-er than MP] [ $\lambda d$. [ $d$-many people read LGB]]]

b. associate $>$ remnant $>$ more

LGB MP-se zyaadaa logõ-ne parh-ii

LGB.f MP-than more people-Erg read-Pfv.f

'More people read LGB than MP.'

LF: [LGB [[-er than MP] $[\lambda d . \lambda x .[d$-many people read $x]]]]$

The precedence requirement provides support for the Direct Analysis. ${ }^{10}$

One implication of the precedence constraint is that associates need to overtly move to the position where -er takes scope. As a result, the locality constraints in Hindi-Urdu phrasal comparatives are just locality constraints on overt movement. This is shown in (30). Relative clauses are islands for overt movement in Hindi-Urdu and an associate cannot move out of a relative clause island to combine with a degree head.

\footnotetext{
${ }^{10}$ Junko Shimoyama (p.c.) has pointed out to us that the constraint under discussion is not a constraint on surface representations. It is a constraint on -er getting all of its arguments. It's just that in the cases under discussion overt scrambling of the associate is needed to bring it into a place where it can combine with -er. If there is an earlier point in the derivation where the associate takes scope over -er, then it is not required to overtly precede -er.

i. $\quad$ [Boman-se zyaadaa kitaabẽ $]_{i}$ Atif-ne $\mathrm{t}_{i}$ parh-ii thĩ:

Boman-than more books.f Atif-Erg read-Pfv.F be.Pst.FPl

'Atif read more books than Boman.'
} 
a. Movement out of a Relative Clause: *

*Arundhati-ne $\mathrm{m}_{i} \mathrm{E}$ vo kitaab [jo $\mathrm{t}_{i}$ likh-ii hai] paṛh-ũ:gaa

Arundhati-Erg I that book Rel write-Pfv.f be.Prs.Sg read-Fut.1MSg

Intended: 'I'll read the book that Arundhati wrote.'

b. Movement of Associate out of a Relative Clause: *

*[Arundhati-ne $]_{i}$ Vikram-se zyaadaa log [vo kitaab [jo $\mathrm{t}_{i}$ likh-ii Arundhati-Erg Vikram-than more people that book Rel write-Pfv.f hai]] paṛh-ẽ:ge

be.Prs.Sg read-Fut.3MP1

Intended: 'More people will read the book that Arundhati wrote than (the book that) Vikram (wrote).'

\subsection{Binding Effects}

An important piece of evidence against the availability of the Direct Analysis in English came from the binding properties of the than-phrase. What we found there was the following generalization: the remnant seemed to be c-commanded by whatever its associate was c-commanded by. This generalization followed under a Reduction Analysis but not under a Direct Analysis. The data from Hindi-Urdu supports a different generalization. The binding properties of the remnant are wholly independent of the binding properties of the associate. They are exactly the binding properties of garden variety PPs determined to a significant extent by considerations of word order. This is what we expect under the Direct Analysis where the remnant is a PP associated with the matrix clause.

The binding properties of PPs in Hindi-Urdu are as follows:

(31) a. They pattern with arguments with respect to Principle B.

b. Subjects can bind reflexives and reflexive possessors into them. Pronominal possessors cannot be coreferent with the subject.

c. Co-arguments that precede the PP c-command it and the PP c-commands co-arguments that follow it.

The than-phrase in Hindi-Urdu has exactly the binding properties outlined above. We demonstrate some of these properties here. Pronominal than-phrases as well as pronominal possessors inside than-phrases display obviation with respect to the subject. To achieve binding with the subject, an anaphor must be used.

a. anaphoric binding, pronominal obviation by subject:

koi-bhii ${ }_{i}$ apne aap-se ${ }_{i} /$ us-se $_{j / * i}$ lambaa nahĩ: ho sak-taa

anyone self's self-than/him-than tall Neg be can-Hab.MSg

'No one ${ }_{i}$ can be taller than $\operatorname{himself}_{i} / \mathrm{him}_{j / * i}$.'

b. anaphoric binding, pronominal obviation of possessors by subject:

Atif $_{i}$ apnii $_{i} /$ us-kii $_{j / * i}$ behen-se lambaa hai

Atif self.f/he-Gen.f sister-than tall be.Prs.Sg

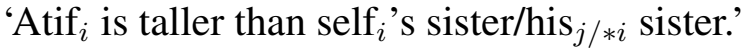


Note that the binding behavior of the than-phrases follows directly from its surface syntax. We do not need to postulate covert clausal structure to explain its binding properties. Very simply, modulo the conditions enumerated in (31), if a matrix pronoun precedes a remnant it cannot refer to an R-expression in it. Otherwise it can.

a. ...[than Peter's ${ }_{i}$ sister's photograph].... pron $_{i} \ldots . .$. : coreference is ok

Sally-kii foto [Peter-kii ${ }_{i}$ behen-kii foto-se] zyaadaa logõ-ne

Sally-Gen.f photo Peter-Gen.f sister-Gen.f photo-than more people-Erg

$\mathbf{u s}^{-k o_{i / j}}$ dii

he-Dat give.Pfv.f

'*More people gave $\operatorname{him}_{i}$ a picture of Sally than a picture of Peter ${ }_{i}$ 's sister.'

(ungrammatical in English, good in Hindi-Urdu)

b. $\quad \ldots$. pron $_{i} \ldots\left[\right.$ than Peter's ${ }_{i}$ sister's photograph].... : coreference is not ok

us-ko ${ }_{i}$ Sally-kii foto [Peter-kii ${ }_{j / * i}$ behen-kii foto-se] zyaadaa he-Dat Sally-Gen.f photo Peter-Gen.f sister-Gen.f photo-than more

logõ-ne dii

people-Erg give.Pfv.f

'*More people gave $\operatorname{him}_{i}$ a picture of Sally than a picture of Peter ${ }_{i}$ 's sister.'

As mentioned earlier, the 'pronoun c-commands the remnant if it c-commands the associate' generalization does not hold for Hindi-Urdu. A matrix pronoun can either precede or follow the remnant. If it precedes the remnant, then from a general fact about Hindi-Urdu syntax, it ccommands the remnant. We therefore need to look at cases where the relevant pronoun follows the remnant but precedes the associate (and hence c-commands it). In such cases, the English generalization would predict that the pronoun cannot refer to a name inside the remnant. As the following example shows, this prediction is incorrect.

$\left[\text { Remnant } . . . . R-E x p_{i} \ldots . .\right]_{j}$ Pron $_{i}$ Associate $\left[\mathrm{t}_{j}\right.$ more $] \ldots \ldots \ldots . .$.

Atif-ne [Ravi-kii ${ }_{i}$ behen-kii foto]-se ${ }_{j} \quad$ us-ko $_{i}[$ Mohan-kii behen-kiifoto $] \quad\left[\mathrm{t}_{j}\right.$ Atif-Erg Ravi-Gen sister-Gen picture-than he-Dat Mohan-Gen sister picture zyaadaa baar] dikhaa-ii

more times show-Pfv.f

'Atif showed Mohan's sister's picture to him more times than Ravi's sister's picture.'

What does all this tell us? It tells us that the Direct Analysis is available in Hindi-Urdu. It also tells us that there is no binding theoretic evidence for the Reduction Analysis. But the lack of evidence does not in itself constitute evidence against the availability of the Reduction Analysis. For that we need to wait for the arguments from scope in $\S 4$.

\subsection{Syntactic Derivations}

In this section, we present explicit derivations of the basic cases of Hindi-Urdu phrasal comparatives and their interaction with scrambling. We want to account for their basic word order and the fact that the than-phrase must precede more but does not need to immediately precede it. We also want to derive the precedence constraints that hold between the associate and more. 
We begin with a phrasal comparative where the associate is a subject. The derivation starts with the assembly of the VP excluding the than-phrase. The than-phrase is merged with more followed by the merger of the subject/associate. The associate moves creating a predicate which is targeted by the movement of the degree phrase - this is an instance of parasitic scope. An important assumption here is that the movement of the Degree Phrase pied-pipes the containing $\mathrm{XP}$, the DP '[Boman-se more] books' in this case. The pied-piped container DP is, however, interpreted in its base position like other cases of pied-piping.

(35) Atif-ne Boman-se zyaadaa kitaabẽ paṛh-ĩ:

Atif-Erg Boman-than more books.f read-Pfv.FPl

'Atif read more books than Boman.'

a. Step 1: Generate 'more books read'

b. Step 2: Merge 'Boman-se' with 'more books': [[Boman-se more] books] read

c. Step 3: Merge subject 'Atif-ne': Atif-ne [[Boman-se more] books] read

d. Step 4: Move 'Atif-ne': Atif-ne $\lambda x .[x$ [[Boman-se more] books] read]

e. Step 5: Move Degree Phrase, which pied-pipes containing DP in overt syntax: LF: Atif-ne [[Boman-se -er] $\lambda d . \lambda x .[x[d$-many books] read] Pronunciation: Atif-ne [[Boman-se more] books] read

Deriving a case where the than-phrase precedes but is discontinuous from more requires an additional step of scrambling.

Boman-se Atif-ne $\mathrm{t}_{i}$ zyaadaa kitaabẽ parh-ĩ:

Boman-than Atif-Erg more books.f read-Pfv.FPl

'Atif read more books than Boman.'

Step 6: Scramble Boman-se over subject:

LF: Boman-se $\lambda y$. Atif-ne [[y-er] $\lambda d . \lambda x$. [ $x[d$-many books $]$ read $]$

Pronunciation: Boman-se ${ }_{i}$ Atif-ne $\left[\left[\mathrm{t}_{i}\right.\right.$ more $]$ books $]$ read

We noted earlier that than-phrases need to precede more. This follows because than-phrases are arguments of more and heads, in general, follow their complements in Hindi-Urdu. One could imagine a derivation where the than-phrase is scrambled out of the Degree Phrase following by a second step of scrambling which moves the Degree Phrase to the left of the than-phrase. This is shown below.

$$
\begin{aligned}
& *\left[\mathrm{t}_{i} \text { zyaadaa kitaabẽ }_{j} \text { Boman-se }_{i} \text { Atif-ne } \mathrm{t}_{j}\right. \text { parh-ĩ: } \\
& \text { more books.f Boman-than Atif-Erg read-Pfv.FPl }
\end{aligned}
$$

Intended Meaning: 'Atif read more books than Boman.'

\section{Unavailable Step 7: Scramble DegP/DP over than-phrase and subject}

The relevant scrambling shown in (37) is unavailable as a violation of Müller (1996)'s Principle of Unambiguous Domination and Fukui (1999)'s Feature-based A-over-A condition. That the source of the ungrammaticality of (37) is the scrambling of a DP out of which another DP has moved out is revealed by the following minimal pair which is acceptable. 
(38) [Boman-se zyaadaa kitaabẽ $]_{j}$ Atif-ne $\mathrm{t}_{j}$ parh-ĩ:

Boman-than more books.f Atif-Erg read-Pfv.FPl

'Atif read more books than Boman.'

Step 6.1: Scramble DegP/DP over subject

In (38), the DegP/DP is scrambled over the subject without creating any ungrammaticality i.e. DegP scrambling is in principle possible but it is blocked when the DegP contains a trace.

Finally we examine cases where overt scrambling of the associate is forced. In these cases, the associate is merged into a position lower than the DegP. Our explanation for the overt scrambling is that in the absence of scope shifting covert movement in Hindi-Urdu, the associate needs overt scrambling to move to a position where it can combine with the DegP. The derivation proceeds as follows.

$$
\begin{aligned}
& \mathrm{MP}_{i} \text { LGB-se zyaadaa logõ-ne } \quad \mathrm{t}_{i} \text { parh-ii } \\
& \text { MP.f LGB-than more people-Erg read-Pfv.f }
\end{aligned}
$$

'More people read LGB than the MP.'

a. Step 1: Generate 'MP read'

b. Step 2: Merge subject:

[[more people] MP read]

c. Step 3: Merge than-phrase with more: [[[LGB-se more] people] MP read]

d. Step 3+: Try to move DegP ([LGB-se more]):

- resulting movement would be semantically uninterpretable as DegP needs to target a predicate and combine with the associate!

e. Step 4: Scramble Associate in front of subject:

LF: MP $\lambda x$. [[[LGB-se more] people] $x$ read]

Pronunciation: $\mathrm{MP}_{i}$ [[[LGB-se more] people $] \mathrm{t}_{i}$ read $]$

f. Step 5: DegP Movement targets predicate created by movement of Associate:

LF: MP [LGB-se -er] $\lambda d . \lambda x$. [[[d-many] people] $x$ read]

Pronunciation: $\mathrm{MP}_{i}[[\mathrm{LGB} \text {-se more }] \text { people }]_{j}\left[\mathrm{t}_{j} \mathrm{t}_{i}\right.$ read $]$

The step right after Step 3 is important. If we do not scramble the associate and attempt to move the DegP, we end up with a semantically illegitimate structure. DegP movement needs to target a predicate of individuals and take the associate as an argument. Neither requirement is met if we move the DegP and leave the associate in-situ. The convergent derivation involves first scrambling the associate and then having DegP movement target the predicate created by the movement of the associate. As before we assume that DegP movement pied-pipes its containing DP.

\section{Scope inside and outside than-phrases}

The difference between Hindi-Urdu and English with respect to the availability of the Reduction Analysis and the Direct Analysis, respectively, is supported by the different interpretive possibilities available to than-phrase internal QPs in the two languages. English phrasal comparatives allow -er to take scope over a than-phrase internal QP. This can be seen in (40). 
(40) More students read every syntax paper than every semantics paper.

(= More students read every syntax paper than read every semantics paper.)

a. than-phrase-internal scope:

[-er [ $\lambda d$.[ $d$-many students read every semantics paper]]]

$[\lambda d$.[d-many students read every syntax paper] $]$

The number of students who read every syntax paper exceeds the number of students who read every semantics paper.

b. than-phrase-external scope: ???

[every syntax paper] $\lambda x$.[every semantics paper] $\lambda y$.

[[-er $[\lambda d$. [ $d$-many students read $y]]]$

$[\lambda d$. [ $d$-many students read $x]]]$

The least read syntax paper was still read by more people than any semantics paper. (paraphraseable as: every syntax paper was read by more students than every semantics paper.)

(Carl Pollard, p.c., paraphrase of (40b) suggested by Lisa Travis)

It is not clear to us whether the reading corresponding to the QP taking scope over -er, i.e. the reading indicated by (40b), is actually available. In other environments, such a reading seems to be quite freely available.

(41) Mary, a first grader, is taller than every third grader in our school.

a. unavailable: - er $>$ every [[-er [ $\lambda d$. [every third grader is $d$-tall]]] [ $\lambda d$.[Mary is $d$-tall]]] $(\approx$ Mary is taller than the shortest third grader. (assuming monotonicity))

b. available: every $>-$ er

[[every third grader] [ $\lambda x$. [[-er [ $\lambda d$.[ $[x$ is $d$-tall] $]]$ [ $\lambda d$.[Mary is $d$-tall $]]]]$

$(\approx$ For every third grader $x$, Mary is taller than $x$.)

(see Heim 2000, 2006, Larson 1988, Schwarzschild and Wilkinson 2002)

The apparent scoping-out behavior in (41) receives a very straightforward treatment within the Direct Analysis. The 3-place -er involved in the Direct Analysis combines with individual arguments and so any quantificational expressions need to QR out. But they can also be handled by a Reduction Analysis which can appeal to the fact that the interpretive restrictions noted for (41) also apply to Mary is taller than every third grader in our school is, a clausal comparative. Then whatever mechanism one uses to handle this clausal comparative can be used to handle (41) by a proponent of the Reduction Analysis.

When can a QP take scope inside a than-phrase and when must it (seem to) scope out? The generalization seems to be as follows.

(42) If a QP c-commands the site of degree abstraction, it must scope out. Otherwise it can take scope within the than-phrase. ${ }^{11}$

\footnotetext{
${ }^{11}$ Jason Merchant (p.c.) has pointed out to us that the scopal properties of a than-phrase-internal QP also seem to depend upon the associate of the than-phrase. When the associate of the than-phrase-internal QP is itself a QP - as is the case in most of our examples - the scoping-out reading seems to be unavailable. But when the associate is a non-quantificational DP, then both the scoping-out and the scoping-in readings are possible.
}

i. More people read Lord of the Rings than every other book by Tolkien.

(i) can mean that 'Lord of the Rings' had more readers than every other Tolkien book pairwise (scoping-out) or 
a. degree abstraction c-commands QP: than-phrase-internal scope ok Craige assigned more students every paper by Hellan than every paper by Klein.

b. QP c-commands degree abstraction: QP must scope out

Craige assigned every first year student more papers than every second year student.

What this generalization tells us is that the need/ability to scope out of a than-phrase is not reducible to a subject/non-subject asymmetry. Instead it is only by making reference to the hierarchical relationship between the remnant and the site of degree abstraction within an abstract clause that this generalization can be stated. This by itself suggests the need for a Reduction Analysis in English.

We saw earlier that both a Direct Analysis and a Reduction Analysis can handle cases of QPs (apparently) scoping over -er. What about cases of QPs scoping below -er? Such cases are easy for a Reduction Analysis to handle. But not for a Direct Analysis, which forces any QPs to scope out. There is simply no other alternative. ${ }^{12}$ We now make a rather strong prediction. Given that we have argued that only the Direct Analysis and not the Reduction Analysis is available for phrasal comparatives in Hindi-Urdu, we predict that the judgments for the HindiUrdu counterpart of (40) will be the mirror image of the English (40) i.e. the scoping-in reading in (40a) will be unavailable and the scoping-out reading in (40b) will be available. This is in fact the case. The Hindi-Urdu counterpart of (40) does not allow for the than-phrase-internal scope reading. The only interpretation available is the external scope reading.

(43) [har syntax paper] [har semantics paper]-se zyaadaa logõ-ne parh-aa every syntax paper every semantics paper-than more people-Erg read-Pfv

'More people read every syntax paper than every semantics paper.' every > -er: available; -er > every: unavailable

To get the than-phrase-internal scope, a clausal comparative must be used.

(44) [jitne logõ-ne har semantics paper parh-aa] [us-se zyaadaa logõ-ne how.many people-Erg every semantics paper read-Pfv that-than more people-Erg har syntax paper parh-aa] every syntax paper read-Pfv

'More people read every syntax paper than did every semantics paper.'

The scope facts thus provide additional support for our two claims. The first is that the Direct Analysis is available in Hindi-Urdu but not in English. This is why Hindi-Urdu allows/forces for than-phrase-internal QPs to scope out in (43) but English does not. The second is that the Reduction Analysis is available in English but not in Hindi-Urdu. The differential availability of the Reduction Analysis explains why QPs can scope-in in the English (40a) but not in the Hindi-Urdu (43).

that the number of Lord of the Rings readers exceeds the number of people who have read all of the other Tolkien novels (scoping-in). We have to leave the derivation of this scoping generalization for future work.

${ }^{12}$ An alternative would become available if we had a higher order -er high that combined with two quantifiers and a predicate of degrees and quantifiers.

(i) $\llbracket-$ er $_{h i g h} \rrbracket=\lambda Q_{(e t) t} \cdot \lambda \mathcal{D}_{d((e t) t) t} \cdot \lambda P_{(e t) t} \cdot \exists d[\mathcal{D}(P, d) \wedge \neg \mathcal{D}(Q, d)]$

Such a higher order -er would allow for a QP to take scope inside the than-phrase even with the Direct Analysis and would generate the desired meaning for (40). But this entry for -er would also allow for a QP to take scope within the than-phrase in cases like (41). Since in Hindi-Urdu neither is a possibility, we must conclude that -er $r_{\text {high }}$ is not available. We speculate that even if $-e r_{h i g h}$ were available, Beck's (1996)/Fox's (2000) constraint against higher order traces would make it unusable. 


\section{Japanese and the Distribution of Degree Heads}

\subsection{The Distribution of Degree Heads in English and Hindi-Urdu}

We have seen for English that the binding data and the scope data rule out the Direct Analysis. Hence only a Reduction Analysis is viable and only the 2-place -er is in use in English. In HindiUrdu, on the other hand, the binding data is compatible with the Direct Analysis. Moreover the precedence constraint, the Single Remnant Restriction and the scope data argue against the Reduction Analysis. But we still need the 2-place -er to handle the more than $n$ cases and correlatives. This means that Hindi-Urdu is a language that has both the 2-place and the 3-place -er but where only the Direct Analysis is in use.

The difference between Hindi-Urdu and English comes down to the following questions. Why does Hindi-Urdu lack the Reduction Analysis? and why does English lack a 3-place -er? The answer for the first question is easier to pin down. Reduction Analyses involve reduction operation that apply to the comparative clause. The relevant reduction operations apply to finite clauses in Hindi-Urdu but as discussed earlier finite clauses cannot appear as complements of postpositions in Hindi-Urdu. Consequently the structures where a Reduction Analysis might have applied are systematically ruled out. This brings us to the second question which is much harder. Here is an initial attempt.

Our initial attempt starts with the idea that the 2-place -er is semantically basic. Let's assume that all languages have access to the 2-place -er from the basic cognitive notion of comparison. The 2-place -er also fits the more general quantificational schema where one of the arguments corresponds to a restrictor and the other to a nuclear scope. The 3-place -er is only induced if there is evidence for it. In English, where the relevant reduction operations are available, there is no evidence that forces the learner to assume a 3-place -er (and a Direct Analysis to go with it). In Hindi-Urdu, however, the relevant reduction operations are unavailable in the complement of -se/'than', forcing the learner to assume a 3-place -er (and a Direct Analysis). ${ }^{13}$

This initial proposal links the availability of 3-place -er very directly to the unavailability of reduction operations in the complement of than. This works for Hindi-Urdu but as we see when we move to the data from Japanese, this is too strong a link. There is good evidence for the 3-place -er in Japanese but also good evidence for reduction operations. We turn to the Japanese facts next.

\footnotetext{
${ }^{13}$ In this context, we can ask why we do not seem to find corresponding 3-place versions of quantifiers over individuals such as every. What would such a 3-place quantifier look like? Mechanically applying the process by which we get the 3-place -er from the 2-place -er to derive a 3-place every from the standard 2-place every yields the following:

(1) $\llbracket$ every $_{3} \rrbracket=\lambda x \cdot \lambda P_{e e t} \cdot \lambda y \cdot[P(x) \subseteq P(y)]$

Our response is that every does not generally combine with individuals and so the syntax does not provide support for the postulation of a 3-place every. There are marginal cases like Every John likes pizza but here it is plausible that proper names like John of type $e$ can type-shift into an et meaning, allowing for us to retain the 2-place entry. This strategy cannot be used with phrasal comparatives where the corresponding type-shift would have to be from type $e$ to type $d t$.
} 


\subsection{A Basic Introduction to Japanese Comparatives}

\subsubsection{The Role of yori}

Japanese comparatives are introduced by yori $(\mathrm{mo})$. In most comparative environments, yori and yorimo seem to be in free variation.
a. Taroo-wa [Hanako-yori(mo)] kasikoi.
Taro-Top Hanako-than smart
'Taro is smarter than Hanako.'
b. Taroo-wa [Hanako-yori(mo)] ooku-no hon-o yonda.
Taro-Top Hanako-than many-Gen book-Acc read
'Taro read more books than Hanako.'

Note that there is no overt degree head - no -er, no more. Nevertheless like in Hindi-Urdu, the yori-phrase must precede the site of degree abstraction. The site of degree abstraction in (46) is in the object and therefore the yori-phrase must precede the object.

a. Taroo-wa [Hanako-yori] omosiroi hon-o yonda.

Taro-Top Hanako-than interesting book-Acc read

'Taro read a more interesting book than Hanako.'

b. *Taroo-wa omosiroi hon-o [Hanako-yori] yonda.

Taro-Top interesting book-Acc Hanako-than read

'Taro read a more interesting book than Hanako.'

Like Hindi-Urdu -se, but unlike English than, yori also functions as the directional postposition 'from'. This is a crosslinguistically well-attested pattern, see Stassen (1985) for details.

(47) yori as a directional postposition:

a. Watasi-wa Tokyo-yori mairimasita.

I-Top Tokyo-from came

'I came from Tokyo.'

b. Watasi-wa Taroo-yori tegami-o moraimasita.

I-Top Taro-from letter-Acc received

'I received a letter from Taro.'

\subsubsection{Combinatorial Properties of yori}

yori can combine with DPs but it can also combine with some case-marked phrases/PPs. As (48) shows, yori can combine with dative marking as well as with the locative postposition. In both cases, the postposition/case-marker can be omitted.

a. DP-(Dat)-yori: dative is optional

John-wa [[Sue-(ni)]-yori] Hanako-ni ooku-no hon-o ageta.

John-Top Sue-Dat-than Hanako-Dat many-Gen book-Acc gave

'John gave more books to Hanako than (to) Sue.'

b. DP-(Loc)-yori: locative postposition is optional 
John-wa [[Kyoto-(de)]-yori] Tokyo-de ooku-no hito-ni atta.

John-Top Kyoto-in-than Tokyo-in many-Gen people-Dat met

'John met more people in Tokyo than (in) Kyoto.'

The DPs that combine with yori cannot have the marking of a structural case: nominative (-ga) and accusative $(-o)$ cannot appear immediately before yori. Yori can also combine with clauses.

a. Taroo-wa [Hanako-ga yonda yori] ooku-no hon-o yonda.

Taro-Top Hanako-Nom read than many-Gen book-Acc read

'Taro read more books than Hanako read.'

b. Taroo-wa [Hanako-ga zassi-o katta yori] ooku-no syoosetu-o katta.

Taro-Top Hanako-Nom magazine-Acc bought than many-Gen novel-Acc bought

'Taro bought more novels than Hanako bought magazines.'

Multiple remnants are possible with yori. ${ }^{14}$

a. [[Taroo-ga Tokyo-de]-yori] Jiroo-ga Kyoto-de ooku-no hito-ni atta. Taro-Nom Tokyo-in-than Jiro-Nom Kyoto-in many-Gen people-Dat met 'Jiro met more people in Kyoto than Taro in Tokyo.'

b. [[Taroo-ga Hanako-ni]-yori] Jiroo-ga Keiko-ni takai purezento-o ageta. Taro-Nom Hanako-Dat-than Jiro-Nom Keiko-Dat expensive present-Acc gave 'Jiro gave a more expensive present to Keiko than Taro to Hanako.'

There are some constraints on the formation of comparatives with multiple remnants in Japanese. The good cases of multiple remnants all involve a Dative phrase/PP that appears immediately before yori. Cases where there is no Dative/PP or where the Dative/PP does not immediately precede yori are ungrammatical.

a. [nominative adverb]-than: *

*[[Taroo-ga kinoo]-yori] Jiroo-ga kyoo ooku-no hito-ni atta.

Taro-Nom yesterday-than Jiro-Nom today many-Gen people-Dat met

'Jiro met more people today than Taro yesterday.'

b. [dative nominative]-than: *

*[[Hanako-ni Taroo-(ga)]-yori] Keiko-ni Jiroo-ga takai purezento-o

Hanako-Dat Taro-Nom-than Keiko-Dat Jiro-Nom expensive present-Acc ageta.

gave

'Jiro gave a more expensive present to Keiko than Taro to Hanako.'

These constraints notwithstanding, it is clear that Japanese allows for reduction operations to apply in the complement of yori. In this respect, it is like English and not like Hindi-Urdu. In contrast to Japanese, multiple remnants were sharply ungrammatical in Hindi-Urdu. Given the tentative proposal advanced at the beginning of this section, we expect to find that Japanese will pattern with English with respect to phrasal comparatives. But this is not what we find. Japanese phrasal comparatives pattern with Hindi-Urdu with respect to the scope and binding tests. It is these tests that we turn to next.

\footnotetext{
${ }^{14}$ There is some speaker variability here. For some speakers, the examples in (50) are slightly degraded.
} 


\subsection{Evidence from Binding and Scope}

We saw in Hindi-Urdu that the binding properties of the than-phrase did not depend upon the binding properties of its associate. This is also true for Japanese. yori-phrases behave like PPs and their binding properties are largely determined by their own structural position, which is determined to a significant extent by word order. The generalization connecting the binding properties of the than-phrase and the associate in English by which the "pronoun c-commands the remnant if it c-commands the associate' generalization does not hold for Japanese.

$\left[\text { Remnant }_{\ldots} . . . \mathbf{R}-\mathbf{E x p}_{i} \ldots\right]_{j} \operatorname{Pron}_{i}$ Associate $\left[\mathrm{t}_{j}\right.$ more $] \ldots \ldots \ldots$.

Hanako-wa [Taroo-no ${ }_{i}$ imooto-no syasin]-yori $_{j}$ kare-ni $_{i}$ [Keiko-no imooto-no Hanako-Top Taro-Gen sister-Gen picture-than he-Dat Keito-Gen sister-Gen syasin]-o [ $\mathrm{t}_{j}$ hinpan-ni] miseta.

picture-Acc frequently showed

'Hanako showed Keiko's sister's picture to him more frequently than Taro's sister's picture.'

So the binding data does not provide support for the Reduction Analysis. By the converse of the logic of the argument used for English, it shows that a Direct Analysis must be available for Japanese. But we do not yet have an argument that the Reduction Analysis is unavailable for Japanese phrasal comparatives. That argument comes from the scopal properties of quantificational yori-phrases in Japanese.

Japanese phrasal comparatives and Japanese clausal comparatives differ systematically in the scopal properties of quantifiers in the complement of yori. Clausal comparatives in Japanese pattern with English in that scopal behavior of yori-phrase-internal quantifiers depends upon their structural configuration. If the yori-phrase-internal quantifier c-commands the degree variable, the quantifier seems to take scope outside the degree clause.

QP 'Dono keizaigakusya-ga' c-commands ' -,', locus of degree abstraction:

$\rightarrow$ QP scopes out yori-clause

[Dono keizaigakusya-ga _-- yonda yori-mo] dono gengogakusya-mo ooku-no every economist-Nom read than-mo every linguist-mo many-Gen ronbun-o yonda.

paper-Acc read

'Every linguist read more papers than every economist read.'

(*-er>every) (every>-er)

But when the yori-phrase-internal quantifier does not c-command the degree variable, it seems to take scope inside the degree clause.

QP 'Dono imiron-no ronbun-o' does not c-command '-_', locus of degree abstraction: $\rightarrow$ QP scopes inside yori-clause

[--- Dono imiron-no ronbun-o yonda yori-mo] ooku-no hito-ga dono every semantics-Gen paper-Acc read than-mo many-Gen people-Nom every toogoron-no ronbun-mo yonda. syntax-Gen paper-mo read 
'More people read every syntax paper than read every semantics paper.'

(-er $>$ every) (*every $>$-er)

Multiple remnant comparatives are similar to full clausal comparatives with respect to scopal judgements. ${ }^{15}$ Japanese phrasal comparatives, on the other hand, pattern with Hindi-Urdu in that yori-phrase internal QPs always scope out.

(55) Japanese Phrasal Comparatives: QP always scopes out

a. Dono toogoron-no ronbun-mo [dono imiron-no ronbun-yori-mo] ooku-no every syntax-Gen paper-mo every semantics-Gen paper-than-mo many-Gen hito-ga yonda.

people-Nom read

'More people read every syntax paper than every semantics paper.'

(*-er $>$ every) (every $>$-er)

b. Dono dansi gakusei-mo [dono zyosi gakusei-yori-mo] ooku-no ronbun-o every male student-mo every female student-than-mo many-Gen paper-Acc yonda.

read

'Every male student read more papers than every female student.'

(*-er>every) (every $>$-er)

Here is a way of interpreting the above facts. Let's begin with the assumption that thanphrase-internal scope requires clausal structure. When there is no overt evidence for a clause, there is no clause. And when there is overt evidence in the form of an actual verb or multiple remnants, there is a clause. Japanese comparatives, under this conception, would have a 'what you see is what you get' flavor to them. In this they would differ from English comparatives where we seem to have a clause even when all we see is a DP.

\subsection{The Precedence Restriction}

Recall from Hindi-Urdu that if the merge site of the associate is lower than the degree head, the associate must move to a position where it overtly takes scope over the degree head.

a. *: Remnant more $\lambda d \ldots d$ Associate

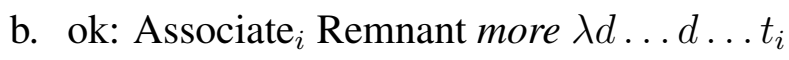

We find this constraint to also be at work with phrasal comparatives in Japanese, which fits with the fact that like Hindi-Urdu, Japanese lacks covert QR.

a. Associate follows the site of degree abstraction (in overt syntax and LF):

*MP-yori ooku-no hito-ga LGB-o yonda.

MP-than many-Gen people-Nom LGB-Acc read

'More people read LGB than the MP.'

b. Associate is fronted and now precedes the site of degree abstraction:

\footnotetext{
${ }^{15}$ It should be noted though that the judgements on quantifiers inside multiple remnant comparatives are somewhat muddied by the fact that multiple remnant comparatives have a mildly degraded status to begin with for many speakers.
} 
LGB-o $_{i} \quad$ MP-yori ooku-no hito-ga $\mathrm{t}_{i}$ yonda.

LGB-Acc MP-than many-Gen people-Nom read

'More people read LGB than the MP.'

This constraint is not operative when yori takes a clausal complement. It is also not operative when yori combines with multiple remnants.

(58) a. Associate follows the site of degree abstraction (in overt syntax and LF):

[MP-o yonda]-yori ooku-no hito-ga LGB-o yonda.

MP-Acc read-than many-Gen people-Nom LGB-Acc read

'More people read LGB than the MP.'

b. Associate is fronted and now precedes the site of degree abstraction:

LGB-o [MP-o yonda]-yori ooku-no hito-ga yonda.

LGB-Acc MP-Acc read-than many-Gen people-Nom read

'More people read LGB than read the MP.'

This distinction between phrasal comparatives and clausal comparatives lends further support to our contention that phrasal comparatives in Japanese do not have a clausal source. If they did, we would expect them to behave like clausal comparatives and not have to obey the precedence constraint.

At this point one could wonder whether the scope difference between English and Japanese/ Hindi-Urdu phrasal comparatives could be related to the fact that the precedence constraint applies in Japanese/Hindi-Urdu, forcing overt scrambling of the associate. Japanese shows that scrambling of the associate does not affect the scopal properties of a than-phrase internal quantifier. First let us consider a clausal comparative where a putative associate follows the degree head. Since here, the than-phrase internal QP does not c-command the site of degree abstraction, we only get than-phrase internal scope.

[Dono imiron-no ronbun-o yonda yori-mo] ooku-no hito-ga dono every semantics-Gen paper-Acc read than-mo many-Gen people-Nom every toogoron-no ronbun-mo yonda.

syntax-Gen paper-mo read

'More people read every syntax paper than read every semantics paper.'

(The number of people who read every syntax paper exceeds the number of people who read every semantics paper.)

(-er $>$ every) $(*$ every $>$-er $)$

Scrambling of every syntax paper to a position preceding the gradable adjective does not change the scope of every semantics paper with respect to -er.

(60) [Dono toogoron-no ronbun-mo] [dono imiron-no ronbun-o yonda yori-mo] every syntax-Gen paper-mo every semantics-Gen paper-Acc read than-mo ooku-no hito-ga yonda. many-Gen people-Nom read

'More people read every syntax paper than read every semantics paper.'

(The number of people who read every syntax paper exceeds the number of people who read every semantics paper.)

(New Reading: For every syntax paper x, the number of people who read x exceeds the 
number of people who read every semantics paper.)

(-er $>$ every) (*every $>$-er)

Scrambling of the associate has predictable scopal effects but crucially these scopal effects are confined to the matrix clause. The quantifier inside the than-clause can still only take scope under -er and within the than-clause. Unlike clausal comparatives, with phrasal comparatives we find obligatory fronting of the associate.

Dono toogoron-no ronbun-mo [dono imiron-no ronbun-yori-mo] ooku-no
every syntax-Gen paper-mo every semantics-Gen paper-than-mo many-Gen
hito-ga yonda.
people-Nom read

'More people read every syntax paper than every semantics paper.'

(*-er>every) (every>-er)

As mentioned above, this in itself suggests that we don't have a hidden clause. If there was, we might have expected phrasal and clausal comparatives to behave alike with respect to fronting of the associate. Furthermore if scrambling of the associate was responsible for the 'every>-er' reading, we would expect (60) to have this reading. And if phrasal comparatives like the one in (61) had a covert clausal structure, we would expect it to allow for the '-er>every' scopal relation on a parallel with (60). So while (61) involves scrambling of the associate, scrambling does not by itself yield the 'every>-er' scopal relation and the difference between English and Japanese does not reduce to the fact that Japanese associates have to be obligatorily scrambled to a position before a gradable adjective. ${ }^{16}$

\subsection{Degree Heads in Japanese}

Yori in Japanese can take a clausal complement. This means that Japanese uses the 2-place degree head. The existence of comparatives where yori combines with multiple remnants show that reduction operations can apply to the clausal complement of yori. Given this, we would expect that comparatives where yori combines with a DP on the surface have a clausal analysis

\footnotetext{
${ }^{16}$ We saw earlier that yori can combine with both a bare DP as well as its case-marked/PP counterpart. The precedence constraint seems to apply only to the bare DP complement and not to the case-marked/PP counterpart.
}

i. a. case-marked remnant: fronting not required:

[Kyoto-de]-yori ooku-no hito-ga Tokyo-de kono eiga-o mita.

Kyoto-in-than many-Gen people-Nom Tokyo-in this movie-Acc saw

'More people saw this movie in Tokyo than in Kyoto.'

b. bare remnant: ungrammaticality without fronting

*[Kyoto]-yori ooku-no hito-ga Tokyo-de kono eiga-o mita.

Kyoto-than many-Gen people-Nom Tokyo-in this movie-Acc saw

'More people saw this movie in Tokyo than Kyoto.'

c. bare remnant: fronting saves the day

[Kyoto]-yori Tokyo-de ooku-no hito-ga kono eiga-o mita. Kyoto-than Tokyo-in many-Gen people-Nom this movie-Acc saw

'More people saw this movie in Tokyo than Kyoto.'

The fact that case marked DP cases pattern with clauses with respect to the precedence restriction suggests a clausal source. 
where the DP-complement of yori is actually the remnant of reduction operations that have applied to a clausal complement of yori.

And yet, as the evidence from scope and precedence shows us that DP complements of yori do not involve a clausal source. Instead they use the 3-place degree head. In other words Japanese is like Hindi-Urdu in employing both a 2-place and a 3-place degree head. But unlike Hindi-Urdu, Japanese does have reductions operations that can apply to the complement of yori making it mysterious why a Reduction Analysis that uses a 2-place degree head is unavailable for Japanese phrasal comparatives. The questions we need to answer are why Japanese allows a 3-place degree head and why it blocks a Reduction Analysis for simple phrasal comparatives.

\section{The Crosslinguistic Distribution of Degree Heads}

What we have found for Japanese is that reduction operations can seemingly apply to comparative clauses to yield multiple remnants but not to yield a single remnant. Why might this be? A very simple answer could come from the properties of the reduction operation. If we had a reduction operation that could only apply if the output of the operation left more than one remnant XP, we would be done. Simple phrasal comparatives could no longer have a clausal source and a 3-place -er would be induced to handle them. Unfortunately we do not know of a reduction operation with these properties. Reduction operations seem to be sensitive to the syntactic object that they apply to and not to the number of XPs, they leave behind. For example, Right Node Raising/Gapping in Japanese, which are plausibly the operations behind the derivation of multiple remnants, are permitted in a one remnant configuration. ${ }^{17}$

Instead of deriving the differences between English and Japanese phrasal comparatives from the properties of the reduction operation, we derive these differences from the different properties of the comparative markers (than/yori) in these languages. We begin by turning around a question that we have been asking: why do Hindi-Urdu and Japanese allow 3-place -er? This question assumes that the 2-place -er is somehow basic and that we need to do something special to induce 3-place -er. The real question to ask we suggest is why 3-place -er seems to be unavailable in English. In fact, we go one step further and make the following proposal:

a. Both 2-place and 3-place entries of -er are available crosslinguistically.

b. However, the syntactic environments where these entries may be used are restricted crosslinguistically by the subcategorizational properties of than/yori/-se.

Let us apply this proposal to the languages under discussion, starting with the easiest case, Hindi-Urdu. We saw that the Hindi-Urdu comparative marker -se only combines with DPs. A DP complement of -se may denote an individual and when it does so, the 3-place -er, which takes individual arguments, must be used. A DP may also denote a degree and in this case, the 2-place -er must be used. This is what happens with correlatives and the more than $n$ cases. Note that a Reduction Analysis is never an option in Hindi-Urdu because -se can only combine with DPs, never with clauses.

Discriminating between English and Japanese phrasal comparatives is harder because both yori and than take clausal complements. But there are two important distinctions between

\footnotetext{
${ }^{17}$ One possibility that we do not pursue here is that Japanese has no degree abstraction in the complement of yori (Kennedy 2007, see also Beck et al. 2004). If Japanese has no degree abstraction in the complement of yori, a 2-place degree head that takes a degree predicate complement becomes impossible. Only the Direct Analysis is possible and the behavior of DP complements follows. But then the analysis of clausal complements, reduced or unreduced, is severely complicated.
} 
than and yori. The first is that yori has, as noted earlier, a non-comparative postpositional use where it means 'from'. Than, however, has only a comparative usage. This has important consequences for their respective subcategorizations. On the surface, than takes a variety of complements, clausal and non-clausal. Since the non-clausal complements can be analyzed as reduced clauses, a single clausal subcategorization is assumed for than. This accords well with the decidedly non-prepositional historical source of modern than; it is related to the Old English than(ne), thon(ne), thaen(ne) and in the Middle English period is even spelled as then. A principle of 'lexical uniformity' might be behind a single subcategorization. Since yori has a (non-comparative) postpositional usage as 'from', it requires a DP subcategorization. Yori also combines with clauses. Therefore, unlike English than, a single subcategorization is not possible for yori. Instead yori subcategorizes for DPs and CPs. The second distinction between yori and than has to do with the headedness of the Deg head in English and Japanese. In English, the Deg head always precedes the than-phrase while in Japanese, the yori-phrase precedes the Deg head.

Since English than only has a CP subcategorization, a CP is always postulated as its complement, even when its overt complement is a DP. Comparative clause CPs only denote degree descriptions, not individuals. As a result only the 2-place -er, which combines with degree descriptions, can be used. The 3-place -er combines with individuals and is therefore unusable with than-phrases.

In Japanese, the complement of yori could be a DP, a clausal structure, or multiple remnants. In the latter two cases, the complement can only be analyzed as a $\mathrm{CP}$ i.e. yori takes a $\mathrm{CP}$ complement and as a result the 2-place degree head must be used. If the complement of yori on the surface is a DP, there are in principle two options: yori takes a DP complement or else it takes a reduced clause whose only remnant is the DP. All our diagnostics tell us that the former option is chosen by the language. When the complement of yori looks like a clause, it is a clause and when it looks like a DP, it is a DP. So what blocks the reduction option, which we have argued plays a role in English?

The reduction operation in Japanese is blocked by an economy constraint that prefers Minimal Structure (see Bošković (1996), Grimshaw (1993), Law (1991), Radford (1994), Speas (1994) for articulations of this constraint). This constraint prefers a DP complement to a CP complement. The constraint can be implemented as a parsing constraint and does not require a transderivational statement. ${ }^{18}$ We have the following implementation in mind. Consider a string where yori follows a DP. When yori is encountered, we have access to its subcategorization which allows it combine with a DP or a CP. The economy constraint prefers the DP subcategorization. Consequently when yori gets a DP complement on the surface, yori actually has a DP complement underlyingly too and therefore only the 3-place degree head may be used. This is how the 'what you see is what you get' property of Japanese comparatives is derived.

We end up with a system where there is no parametrization of lexical entries with respect to degree heads. All languages have the 2-place and the 3-place degree heads. But the usability of a particular head in a particular language is influenced by factors such as the properties of

\footnotetext{
${ }^{18}$ It seems to us that a transderivational statement of this constraint faces the following challenge. Transderivational economy constraints are always stated upon a comparison class. The comparison class could be defined in terms of the numeration or in terms of the meaning. The numerations of phrasal and clausal comparatives are clearly distinct so the meaning direction seems more promising. But now recall that phrasal comparatives in Japanese force quantifiers to scope out in contrast to clausal comparatives which do not. This means that a reduction structure and a direct structure where the complement of yori was a quantifier would have distinct meanings and the economy constraint would not block the reduction structure, contrary to fact.
} 
comparative markers (than, yori, -se), headedness of degree heads, a preference for minimal structure and a preference for a single subcategorization. -se is simply unable to combine with finite clauses blocking the Reduction Analysis and making the 2-place -er unavailable (for the most part) in Hindi-Urdu. yori can combine with both DPs and CPs while than combines only with CPs, leading to the observed differences between English and Japanese comparatives. We conclude this paper with some discussion of the remaining factors: the preference for Minimal Structure, the role of directionality and the preference for a single subcategorization.

\subsection{The Preference for Minimal Structure and Sluicing in Japanese}

The minimal structure constraint we invoked to keep yori from treating DPs like CPs might seem to be too strong. It could, in principle, block any instance of an overt DP being analyzed as the remnant of a reduced clause. One such well attested case is that of sluicing and as we see below, sluicing is possible in Japanese.

a. Dareka-ga kita ga, watasi-wa [dare ka] wakara-nai.

someone-Nom came but I-Top who Q know-Neg

'Someone came, but I don't know who.'

b. Taroo-ga dareka-ni atta ga, watasi-wa [dare-ni ka] wakara-nai.

Taro-Nom someone-Dat met but I-Top who-Dat Q know-Neg

'Taro met with someone, but I don't know who.'

But there is an important difference between sluicing and the comparative cases due to which sluicing does not fall under the purview of the 'DPs over CPs' minimal structure principle. Note that the 'DP complements' of wakara 'know' end with a Q particle. This is enough to indicate that we have a CP. And wakara can certainly combine with a CP. If the Q particle were missing, the DP would not be analyzed as a CP. Instead it would be treated as an ordinary DP argument of wakara 'know' (modulo its special wh/existenial semantics). So the facts from sluicing are completely compatible with our minimal structure principle.

\subsection{The Role of Directionality}

We have argued that the fact that yori phrases precede the degree head in Japanese is one of the factors that plays a role in determining the properties of phrasal comparatives in that languages. The grammar of Japanese exploits a local ambiguity in subcategorization created by the fact that yori functions both as a comparative marker and the postposition 'from'. Since the yoriphrase precedes the degree head, at the point yori is encountered, we do not know which yori we have and then the minimal structure constraint argues against the postulation of a reduced clause. One could wonder why the appeal to directionality is needed. Would the fact that yori functions as 'from' not be enough?

The appeal to directionality is motivated by two kinds of data. The first concerns Hebrew phrasal comparatives. Like Japanese, the Hebrew comparative marker $m i$ - also functions as 'from'. But Hebrew phrasal comparatives pattern with English with respect to binding and scope (Eytan Zweig (p.c.)). There is an important difference between Hebrew and Japanese though - $m i$-phrases in Hebrew follow the degree head while Japanese yori-phrases precede the degree head. Because of this difference, there is no local ambiguity at the point at which mi- is encountered in Hebrew and only the reduced CP analysis, which involves the 2-place head, is available. 
The second kind of data that points to the role of directionality comes from English. We have worked with the idea that English than always takes a CP complement and while this is true for comparatives, there are some domains where it is hard to postulate a clausal analysis for the DP complement of than: ${ }^{19}$

a. Crimes other than murder are widespread in Bessarabia.

b. I met with a student other than Jon.

We do not have a full explanation for why the apparent DP taking properties of than in other than do not permit than in general to have a DP subcategorization in contrast to Japanese. But directionality seems to play a role here. Comparative yori-phrases in Japanese precede the abstract Degree head. As a result, when yori is encountered, it is locally ambiguous between a locative and a comparative usage. In English, than follows its licensor, be it more or other. Consequently it is not locally ambiguous.

\subsection{The Preference for a Single Subcategorization}

The motivation for our proposal that than only takes a CP complement underlyingly can also be questioned. English than certainly has a non-prepositional origin; as we noted earlier, it is related to the Old English than(ne), thon(ne), thaen(ne) and in the Middle English period is spelled as then. But certainly now and in fact, even going back to the Middle English period, the complement of than did not have to match its associate in case.

John is taller than $\mathrm{me}_{\text {normal }} / \mathrm{I}_{\text {formal/uncommon/marked }}$.

Middle English (Beatrice Santorini p.c.)

a. $\operatorname{Case}($ Associate $)=$ Case $($ Remnant $)=$ Nominative

i. for they are stronger then we. (AUTHOLD-E2-H,XIII,20N.911)

ii. but heare you my maisters, though mistresse Winchcomb goe in her hood, I am as good as shee, (DELONEY-E2-H,79.330)

b. $\operatorname{Case}($ Associate $)=$ Nominative $\neq$ Case $($ Remnant $)=$ Oblique

i. my care \& tender love to yu is Great hoping God will make $\mathrm{y}=\mathrm{u}=\mathrm{a}$ comfort to me in my old age $\& \mathrm{y}=\mathrm{t}=\mathbf{y}=\mathbf{u}=$ will be better advised then them $\mathrm{y}=\mathrm{t}=$ have bin a griefe of heart to me $\&$ a ruin to themselves $\&$ would consume $\mathrm{y}=\mathrm{t}=$ before $\mathrm{o}=\mathrm{r}=$ faces $\mathrm{w}=\mathrm{ch}=$ their friendes have bin carefull to get for them. (JOPINNEYE3-P2,48.9)

ii. Lory. Here comes a Head, Sir, [who/that - BES] would contrive it better than us both, if he wou'd but joyn in the Confederacy. (VANBR-E3-P2,29.195)

In Middle English (and more reliably in Modern German), the case matching between the remnant and the associate can be taken to provide evidence for a reduced clause. By the time we come to Modern English, this kind of evidence is essentially gone. But if we are right, the grammar continues to analyze than as taking CP complements. Pending a deeper explanation, we have to conclude that the economy considerations that favor a single subcategorization for than are not sensitive/dependent on surface evidence of this sort. They must be innate.

\footnotetext{
${ }^{19}$ Also relevant are the cases of DP-internal subcomparatives such More professors than [students] attended the talk discussed by Keenan (1987).
} 


\section{References}

Beck, S. (1996) Wh-constructions and transparent Logical Form, Doctoral dissertation, Universität Tübingen, Tübingen, Germany.

Beck, S., T. Oda, and K. Sugisaki (2004) "Parametric Variation in the Semantics of Comparison: Japanese vs. English,” Journal of East Asian Linguistics 13, 289-344.

Bhatt, R., and V. Dayal (2007) "Rightward Scrambling as Rightward Remnant Movement," Linguistic Inquiry 38:2, 287-301.

Bhatt, R., and R. Pancheva (2004) "Late Merge of Degree Clauses," Linguistic Inquiry 34:3, $1-45$.

Bhatt, R., and S. Takahashi (2007) "Direct comparisons: Resurrecting the direct analysis of phrasal comparatives," in M. Gibson and T. Friedman, eds., Proceedings of SALT XVII, Cornell University, Ithaca, NY, CLC Publications.

Biberauer, T., A. Holmberg, and I. Roberts (2007) "Disharmonic word-order systems and the Final-over-Final-Constraint (FOFC)," in Proceedings of the Incontro di Grammatica Generativa.

Bošković Željko (1996) "Selection and the categorial status of infinitival complements," Natural Language and Linguistic Theory 14:2, 269-304.

Brame, M. (1983) "Ungrammatical notes 4: Smarter than me," Linguistic Analysis 12, 323328.

Fox, D. (2000) Economy and Semantic Interpretation, Linguistic Inquiry Monographs 35, MIT Press, Cambridge, Massachusetts.

Fukui, N. (1999) "An A-over-A perspective on locality," in M. Muraki and E. Iwamoto, eds., Linguistics: In search of the human mind - A festschrift for Kazuko Inoue, Kaitakusha, Oxford, 109-129.

Grimshaw, J. (1993) "Minimal Projection, Heads and Optimality," in Rutgers University Center for Cognitive Science Technical Report, volume 4.

Hackl, M. (2001) Comparative Quantifiers, Doctoral dissertation, Massachusetts Institute of Technology, Cambridge, Massachusetts. Distributed by MIT Working Papers in Linguistics.

Hankamer, J. (1973) "Why there are two than's in English?" in Papers from the Ninth Regional Meeting of the Chicago Linguistics Society, Chicago Linguistics Society, Chicago, 179191.

Heim, I. (1985) "Notes on Comparatives and Related Matters," unpublished manuscript, University of Texas at Austin.

Heim, I. (2000) “Degree Operators and Scope," in Proceedings of SALT X, Cornell University, Ithaca, NY, Cornell Linguistics Club, 40-64.

Heim, I. (2006) "Remarks on Comparative Clauses as Generalized Quantifiers," massachusetts Institute of Technology manuscript.

Holmberg, A. (2000) "Deriving OV order in Finnish," in P. Svenonius, ed., The Derivation of $V O$ and $O V$, John Benjamins, Amsterdam, 123-152.

Kayne, R. S. (1994) The Antisymmetry of Syntax, Linguistic Inquiry Monographs 25, MIT Press, Cambridge, MA. 
Keenan, E. (1987) “Multiply-headed Noun Phrases,” Linguistic Inquiry 18:3, 481-490.

Kennedy, C. (1997) Projecting the Adjective: The Syntax and Semantics of Gradability and Comparison, Doctoral dissertation, University of California, Santa Cruz, Santa Cruz, California. published in 1999 by Garland in the Outstanding Dissertations in Linguistics series.

Kennedy, C. (To appear) "Modes of Comparison," in Proceedings of CLS 43.

Larson, R. (1988) “Scope and Comparatives," Linguistics and Philosophy 11:1, 1-26.

Law, P. (1991) Effects of Head Movement on Theories of Subjacency and Proper Government, Doctoral dissertation, Massachusetts Institute of Technology, Cambridge, Massachusetts. Distributed by MIT Working Papers in Linguistics.

Lebeaux, D. (1990) "Relative clauses, licensing, and the nature of the derivation," in Proceedings of NELS 20, Amherst, Massachusetts, GLSA, 318-332.

Lechner, W. (2001) "Reduced and phrasal comparatives," Natural Language and Linguistic Theory 19, 683-735.

Lechner, W. (2004) Ellipsis in Comparatives, Mouton de Gruyter, Berlin.

Mahajan, A. K. (1997) “Universal Grammar and the Typology of Ergative Languages," in A. Alexiadou and T. A. Hall, eds., Studies on Universal Grammar and Typological Variation, John Benjamins, Amsterdam, 35-57.

Merchant, J. (2006) "Phrasal and clausal comparatives in Greek and the abstractness of syntax," unpublished University of Chicago Manuscript.

Müller, G. (1996) “A Constraint on Remnant Movement," Natural Language and Linguistic Theory 14:2, 355-407.

Nevins, A., and P. Anand (2003) "Some AGREEment matters," in G. Garding and M. Tsujimura, eds., Proceedings of WCCFL 22, Somerville, MA, Cascadilla Press, 370-383.

Nissenbaum, J. W. (2000) Investigations of Covert Phrase Movement, Doctoral dissertation, Massachusetts Institute of Technology, Cambridge, Massachusetts. Distributed by MIT Working Papers in Linguistics.

Pancheva, R. (2006) "Phrasal and Clausal Comparatives in Slavic," in Formal Approaches to Slavic Linguistics 14: The Princeton Meeting.

Pancheva, R. (2007) “Than,” handout of Talk Presented at GLOW XXX, Tromsø, April 14.

Schwarzschild, R., and K. Wilkinson (2002) "Quantifiers in Comparatives," Natural Language Semantics 10, 1-41.

Speas, M. (1994) "Null Argument in a Theory of Economy of Projection," in E. Benedicto and J. Runner, eds., University of Massachusetts Occasional Papers in Linguistics, volume 17.

Stassen, L. (1985) Comparison and Universal Grammar, Blackwell, Oxford.

Stechow, A. von (1984) "Comparing semantic theories of comparison," Journal of Semantics 3:1, 1-77.

Takahashi, S., and S. Hulsey (2008) "Wholesale late merger: Beyond the A/A'-distinction,” to appear in Linguistic Inquiry. 